\title{
Recomendações para o Uso Salutar das Tecnologias Digitais na Dromocracia Cibercultural
}

\author{
Bruna S. Silva ${ }^{1}$, Henrique N. Schneider ${ }^{2}$ \\ ${ }^{1}$ Departamento de Computação - Universidade Federal de Sergipe UFS) \\ Aracaju - SE - Brazil \\ ${ }^{2}$ Departamento de Computação - Universidade Federal de Sergipe (UFS) \\ Aracaju - SE - Brazil \\ Bruna.silva@dcomp.ufs.br, hnseterra.com.br
}

Abstract. This article, the result of research at the level of Scientific Initiation at the $x x x$, reflects on contemporary society in the light of the concept of cybercultural dromocracy, based on the writings of Trivinho (2007) and Virilio (1984), which has speed as a vector that dictates human behavior in the world of work and entertainment. The logic of cybercultural dromocracy has been developing diseases such as nomophobia, which means the fear of being without a cell phone or the internet. Thus, the present work proposes recommendations to avoid disorders caused by nomophobia.

Resumo. Este artigo, fruto de pesquisa em nível de Iniciação Científica na xxx, reflete sobre a sociedade na contemporaneidade à luz do conceito de dromocracia cibercultural, fundamentado nos escritos de Trivinho(2007) $e$ Virilio (1984), que tem a velocidade como vetor que dita o comportamento humano no mundo do trabalho e no mundo do entretenimento. A lógica da dromocracia cibercultural, vem desenvolvendo enfermidades como a nomofobia, que significa o medo de ficar sem o telefone celular ou da internet. Assim, o presente trabalho discute e oferece recomendações para evitar os transtornos causados pela nomofobia.

\section{Introdução}

O presente artigo é fruto de uma pesquisa em nível de Iniciação Científica na Universidade Federal de Sergipe (UFS), desenvolvida no Grupo de Estudos e Pesquisa em Informática na Educação (GEPIED), vinculado ao Departamento de Computação, com apoio do Conselho Nacional de Desenvolvimento Científico e Tecnológico (CNPq). Trata-se de uma pesquisa bibliográfica e descritiva, utilizando material bibliográfico para compreender a Dromocracia Cibercultural, relacionando-a ao fenômeno da Nomofobia a fim de apresentar recomendações para evitá-la.

Para compreender a sociedade contemporânea e seus acontecimentos sociais, culturais e tecnológicos é necessário compreender o seu modus vivendi. Segundo Virilio (1984) a cidade é resultado da guerra ou da preparação para a guerra. Tudo isso é articulado pelo vetor velocidade, relacionado com os processos históricos bélicos e civis. Tal vetor orienta o anseio humano por avanços tecnológicos implicando violentamente na relação homem/espaço. 
Diante disso, procurou-se entender as consequências ocasionadas pelo uso indiscriminado das tecnologias digitais na contemporaneidade (mais especificamente $o$ smartphone) e em oferecer soluções específicas para um uso salutar dessas tecnologias em um cenário de crescente dependência por dispositivos de conexão com a internet. Para tal, primeiramente, foi analisada a sociedade contemporânea à luz do conceito sociológico Dromocracia Cibercultural [Trivinho 2007]. Feito isso, foi necessário compreender a propedêutica da nomofobia, relacionando-a ao fenômeno sociológico. Assim, a pesquisa foi concluída com o desenvolvimento de uma lista de recomendações para evitar a nomofobia. Espera-se que tal lista atue como um vetor de prevenção a essa nova patologia.

\section{A Contemporaneidade à luz da Dromocracia Cibercultural}

O primeiro objetivo foi desenvolver conhecimento acerca do estado dromocrático cibercultural vivido pela sociedade contemporânea. Para isso, refletiu-se sobre os quatro pontos que Trivinho aborda em sua obra "Dromocracia Cibercultural: lógica da vida humana na civilização mediática avançada", de 2007: o conceito de velocidade, a violência da velocidade, dromoapidão e dromopatologias. No que se compreende por velocidade, o autor afirma como fenômeno de imposição que organiza e modela toda a existência social, cultural, política e econômica da civilização contemporânea. $\mathrm{O}$ vetor velocidade é progressivo e ocupa os dois mundos: do trabalho, em sua escala de produtividade, ou seja, maior produção em menor tempo; e o mundo do lazer, na escala de intensidade, ou seja, maior aproveitamento no menor período de tempo.

A velocidade é uma forma de violência, pois apresenta-se de forma sutil e invisível como fenômeno de imposição. É uma violência simbólica, seguindo o conceito de Bourdieu (1983), ou seja, o dominado não se percebe como vítima e não se opõe ao opressor. Isso se deve ao seu caráter operativo, sua eficácia na lógica da vida social, segundo Trivinho(2007), "abundantemente estetizada por abstrações culturais". Enfim, a violência da velocidade se apresenta como combustível essencial da civilização contemporânea, opera movendo a tudo e a todos, servindo-se da estrutura do capitalismo globalizado, fazendo com que a lógica humana sirva ao seu vetor. [Trivinho 2007].

Em tal contexto é importante explicar o termo Dromocracia. Dromo, do grego, significa rapidez e Dromocracia e é, segundo Trivinho (2007), o regime da velocidade. No cenário de manutenção e otimização constante das taxas de velocidade é imposto silenciosamente a dromoaptidão, o caráter de seguir o ritmo da velocidade, antecipar-se ao funcionamento do sistema tecnológico e, com isso, alimentar o vetor.

A dromoaptidão, segundo Trivinho (2007), é um processo de gerenciamento infotécnico da existência. O poder na cibercultura é definido por senhas de acesso, são elas, segundo o autor: objeto infotecnológico (hardware); produtos ciberculturais compatíveis(softwares); status irrestrito de usuário da rede; capital cognitivo necessário para operar os três fatores e capacidade geral de acompanhamento regular de todo o sistema. Assim, faz-se necessário capacidade de dominar, possuir e saber operar exemplares atualizados. Aquele que contrapõe a lógica ou não consegue acompanhar o vetor é excluído do meio presente. 
O capitalismo e seu caráter de produção em massa é citado por Trivinho (2007) como o modo mais dromocrático existente atrelado a sua fase tecnológica: a cibercultura. As corporações do ramo trabalham lançando versões de maior potência, o que o autor chamou de reciclagem estrutural, que traduz-se na procura por mais velocidade, processamento, armazenamento e facilidade, em um processo ascendente de conquista de mercado e maximização do capital investido. Nesse contexto, o autor aponta que a dinâmica dromoapta é atrelada à ideia de felicidade, formando uma minoritária elite cibercultural e, na base, os novos pobres, os miseráveis da informática. Dessa forma, a regra do regime não é a inclusão, mas a exclusão.

A tentativa progressiva de acompanhar um vetor que nunca para de crescer, faz com que a sociedade viva em uma constante angústia. Trivinho (2007), metaforicamente, compara a exclusão com à idéia de morte. Pois, se morrer é desaparecer, quem está privado do acesso e carente do capital dromocrático cibercultural desaparece individualmente e sua vida se emaranha no círculo do subemprego ou desemprego infotecnológico: é uma morte simbólica própria da cibercultura. O medo da exclusão e a exigência compulsória pela dromoaptidão é apontado como um pesado fardo para o cérebro humano, sendo causador de stress, neurastenia, TOC, depressão crônica e pânico, entre outras enfermidades urbanas ligadas à mente.

O vetor velocidade e a lógica da reciclagem estrutural estão por trás dos avanços tecnológicos observados no século XXI. Com isso, é sob à luz desta análise que apontamos no presente artigo a problemática do uso acrítico das tecnologias digitais móveis e os possíveis efeitos patológicos desenvolvidos pelo seu uso excessivo.

\section{Nomofobia: Comportamento Patológico Provocado Pela Perda da Conexão com a Internet}

O Segundo objetivo do projeto de pesquisa foi conhecer a propedêutica da nomofobia a partir de estudos especializados. Segundo King e Nardi (2013), a nomofobia está relacionada à expressão inglesa "No Mobile Phobia", que significa a fobia de ficar sem o telefone celular. Segundo os autores, a nomofobia é "um transtorno do mundo moderno" relacionado ao "medo de ficar incomunicável, longe do telefone celular ou internet". [King e Nardi 2013].

Segundo Senador (2018), a nomofobia abrange todos os dispositivos digitais, mas seu principal foco é o celular por conta da facilidade que este dispositivo proporciona, principalmente os smartphones. Estes foram popularizados pela empresa Apple a partir de 2007, com o iPhone, após introdução de um browser completo em HTML 5 com uma interface de hardware compacta e fácil de usar [Apple INC. 2007]. Tal avanço possibilitou uma expansão junto à popularização do acesso às redes sociais [Senador 2018]. Hoje, o acesso as redes funcionam como novo padrão de comportamento. Portanto, é uma nova conversão social do nativo digital: transformar as relações sociais em relações digitais.

Em 2014, Bragazzi e Del Punte publicaram, no DovePress journal, uma proposta para incluir a nomofobia no V Manual Diagnóstico e Estatístico de Transtornos Mentais (DSM-V), que é o manual padrão de avaliação de doenças psiquiátricas. Nela os autores 
definem a nomofobia como o distúrbio da sociedade digital contemporânea que resulta no medo patológico de ficar fora do contato com as tecnologias. Para compor a justificativa, são listados alguns sintomas como: gastar muito tempo no celular; sentir-se ansioso na falta do celular e evitar lugares que não pode utilizar o aparelho; olhar constantemente para a tela; ir a todos os lugares com o celular, inclusive levá-lo a cama na hora de dormir; ter poucas interações sociais face-a-face e preferir comunicar-se a partir das tecnologias; ouvir constantemente o toque(ringtones), mesmo não havendo. $\mathrm{Na}$ época, a pesquisa relatou que as pessoas checam seu celular 34 vezes por dia. Segundo Senador (2018) pode chegar a 150 vezes ao dia. A nomofobia não foi incluída ao DSM -V, porém não se pode ignorar seus efeitos psicopatológicos supracitados.

Como resultado desta pesquisa de Iniciação Científica, afirma-se que a nomofobia é consequência da Dromocracia Cibercultural. Por conta do apelo por velocidade na comunicação, houve a popularização dos smartphones. Este par se retroalimenta, pois as tecnologias móveis são ferramentas importantes de suporte ao vetor velocidade.

\section{Resultados: Recomendações para Evitar a Nomofobia}

Contextualizado o processo que rege a sociedade contemporânea e apontado uma das consequências trazida por ele, o presente tópico apresenta resultados do projeto: recomendações para evitar o transtorno da nomofobia.

As recomendações listadas no relatório final do projeto foram separados, sob critério de organização, nos seguintes tópicos: desintoxicação digital diária, que situa-se como informativo geral; uso de aplicativos em smartphones e computadores (PC), que servem como guia para uma prática diária; desintoxicação digital para crianças, complementando as recomendações.

Para compor a desintoxicação digital diária, utilizou-se o estudo do instituto DELETE, que é o primeiro núcleo do Brasil especializado em Detox Digital. Foi idealizado pela Psicóloga clínica Anna Lucia Spear King e pelo Pesquisador Eduardo Guedes, na Universidade Federal do Rio de Janeiro(UFRJ). A importância da fiscalização diária deve-se ao caráter dominante do vetor dromocrático e da normalidade em que o uso das tecnologias digitais apresentam.

O instituto estabelece 10 passos para a Desintoxicação Digital que se encaixa como recomendações que podem evitar a nomofobia. São eles:

I, Bom senso para que o uso das tecnologias não se torne abuso no cotidiano;

II, Fique atento às consequências físicas (privação de sono, dores na coluna, problemas de visão) e psicológicas (depressão, angústia, ansiedade) devido ao uso abusivo das tecnologias; III, Dose o uso de tecnologias no cotidiano. Verifique se seu desempenho acadêmico, no trabalho, na família ou pessoal estão sendo prejudicados pelo uso abusivo das tecnologias; IV, Reflita sobre seus hábitos cotidianos e faça diferente; V, Não troque atividades, compromissos ou encontros ao ar livre para ficar conectado às tecnologias; VI, Prefira uma vida social real à virtual. Escolha relacionamentos e amizades reais ao invés de virtuais; VII, Pratique exercícios físicos regularmente. Crie intervalos regulares durante o uso das tecnologias fazendo alongamentos; VIII, Não abale o seu humor com publicações virtuais. Não acredite em tudo o que é postado e cuidado com o que você publica na internet; IX, Valorize suas relações pessoais, sociais e familiares. Não troque 
estas relações no dia a dia para ficar utilizando as tecnologias; X, Jogue o lixo eletrônico no local correto. Pense no meio ambiente, recicle os aparelhos fora de uso e evite a troca frequente sem necessidade. [Instituto Delete 2014].

No tópico uso de aplicativos em smartphones e computadores (PC), foram analisados alguns aplicativos da categoria Produtividade, da loja de aplicativos para Android: PlayStore. Sob a justificativa da afirmação de Trivinho (2007), que a arte pode, com sua liberdade de criação semiótica, ir contra a sua própria politização no âmbito da dromocracia, através da compreensão do contexto social-histórico, da autocrítica, jogando o conservadorismo das técnicas, da tecnologia e dos media contra ele mesmo. Além do papel fundamental da arte na crítica à cibercultura, pode-se utilizá-la como meio de combate aos males que este regime acarreta. Assim os smartphones e suas aplicações, como na arte, podem servir de vacina e antídoto ao seu próprio uso indiscriminado.

Com isso, foram citados 13 (treze) aplicativos, separados e justificados nas seguintes categorias: Cálculo do uso de dados; Auxílio no estabelecimento de metas; Princípios de gamificação; Controle de uso de determinados aplicativos e Controle rígido via pagamento de multa. Para computadores, foram analisados extensões para navegadores, com opções de listagem de consumo, e sistemas que bloqueiam determinadas aplicações.

No tópico Desintoxicação Digital para Crianças, foi analisado as medidas da Cartilha Digital oferecida, também, pelo instituto DELETE. Segundo a Cartilha Digital (2017) mais do que nunca é necessário ao começar a usar tecnologias, além da educação social, uma "educação digital". Deve-se tornar as crianças adultos conscientes dos benefícios e prejuízos da tecnologia e dos limites de uso/abuso. Essa educação visa evitar consequências psicológicas, como intensificação da ansiedade e depressão, e físicas, como:

[...] obesidade por sedentarismo, diabetes, problemas de visão, problemas de articulação, tendinite por esforço repetitivo ao usar teclados, problemas de coluna lombar e/ou cervical (ex: posturas indevidas durante o uso ou de tanto baixar a cabeça para olhar o telefone celular diversas vezes por dia, por meses e anos seguidos) e de postura em geral, devido à inadequação do mobiliário usado. [King, A.L.S. et al. 2017].

Além disso, é importante salientar a importância de procurar profissionais da saúde (psicólogos e/ou psiquiatras) para um diagnóstico preciso. Segundo Bekaroğlu1 e Y1lmaz (2019), o tratamento cognitivo-comportamental (TCC) pode ser utilizado para auxiliar no desenvolvimento de habilidades de autocontrole, auxiliando pessoas que já não conseguem regular o uso. Outra terapia, destacada pelos autores, é a psicoterapia existencial, cujo objetivo é ajudar o indivíduo no encontro com a autenticidade de sua existência [TEIXEIRA 2006], assim, o tratamento auxilia no questionamento dos motivos do uso excessivo do celular e das mídias digitais e ajuda a definir um estilo de vida mais saudável [BEKAROĞLU1 e YILMAZ 2019]. 


\section{Conclusão}

Como vimos, a nomofobia é consequência do regime dromocrático na sociedade tecnologizada. $\mathrm{O}$ vetor velocidade expande sua atuação, cada vez mais alimentando a si mesmo com inovações tecnológicas facilitadoras, como é o caso do smartphone. Com isso, é necessário pensar seu uso com criticidade e seguir recomendações a fim de não adoecer.

As medidas estudadas e relacionadas no tópico 4 compõem um caso básico de recomendações. Elas atuam, mesmo que superficialmente, para resolver um problema que, mesmo não sendo ainda considerado uma patologia, tende a constituir-se numa enfermidade urbana da sociedade tecnologizada.

Portanto, esperamos que esta discussão atue como vetor de alerta e prevenção da nomofobia, pois não podemos abster-nos das facilidades oferecidas pelos serviços presentes nos aplicativos disponíveis na internet e que estão acessíveis por meio da computação móvel.

\section{Referências}

Apple Inc. [US]. (2007) "Apple Reinvents the Phone with iPhone". Apple Inc [US]. https://www.apple.com/newsroom/2007/01/09Apple-Reinvents-the-Phone-with-iPho ne/, December.

Bekaroğlu1, E. \& Yılmaz T. (2019). Nomophobia: Differential Diagnosis and Treatment. Psikiyatride Güncel Yaklaşımlar-Current Approaches in Psychiatry, 12(1):131-142, doi: 10.18863/pgy.528897.

Bourdieu, P. (1983). Questões de sociologia. Rio de janeiro, Marco Zero.

Bragazzi, N.L. \& Del Puente, G. (2014). A proposal for including nomophobia in the new DSM-V, Psychology Reseach and Behavior Management. Dovepress journal, $155-160$.

Instituto Delete (2014). Delete uso consciente de tecnologias: 10 passos para a desintoxicação digital. $\quad$ Retrieved from https://www.institutodelete.com/comofunciona.

King A.L. \& Nardi A. E. (2013). Novas tecnologias: uso e abuso. In Associação Brasileira de Psiquiatria; Nardi AE, Silva AG, Quevedo JL, organizadores. PROPSIQ Programa de Atualização em Psiquiatria: Ciclo 3 (pp. 9-27). Porto Alegre, RS: Artmed/Panamericana.

King, A. L. S., Guedes, E., Nardi, A. E. (2017). Cartilha Digital. Rio de Janeiro: EducaBooks.

Senador, A. (2018). Nomofobia 2.0 e outros excessos na era dos relacionamentos digitais. São Paulo: Aberje.

Teixeira, J. A. C. (2006). Introdução à psicoterapia existencial. Análise Psicológica, 24(3), 289-309. 2 Retrieved from http://www.scielo.mec.pt/scielo.php?script=sci arttext\&pid=S0870-823120060003 $00003 \& \operatorname{lng}=p t \& t \operatorname{lng}=p t$

Trivinho, E. (2007). A Dromocracia Cibercultural: Lógica da vida humana na civilização mediática avançada. São Paulo: Paulus.

Virilio, P. (1984). Guerra Pura: A militarização do cotidiano. São Paulo, Brasiliense. 